\title{
Quebec's new e-health records may spur change
}

$\mathrm{Q}$ uebec's adoption of a single system of electronic health records across its 34 hospitals is prompting calls for a reassessment of Ottawa's ehealth strategy.

The Government of Quebec wants to rationalize the many competing electronic health record (EHR) systems purchased by hospitals, which are often partly funded by Canada Health Infoway (the federal agency that has invested $\$ 2.1$ billion since 2001 in often-incompatible systems). Rationalizing will help overcome longstanding problems with the lack of "interoperability" between competing and intentionally incompatible commercial EHR systems.

To help break the information logjam, Quebec Health Minister Dr. Gaétan Barrette announced on Dec. 17 that all hospitals will now be required to implement Cristal-Net, a homegrown system developed on a not-for-profit basis by clinician-scientists in Québec City and Grenoble, France.

Cristal-Net, which has been tested in the five Québec City hospitals, will reduce costs while improving the movement of records between hospitals throughout the province, says Jean Boulanger, the systems's director of information technology.

Quebec's decision sends an important signal to the rest of the country, says Joe Cafazzo, director of the Centre for Global eHealth Innovation at the University of Toronto. "There was an assumption made that [the software] industry would solve the interoperability problem, but they didn't because it wasn't in their interest, so perhaps Quebec's decision isn't surprising," says Cafazzo.

Infoway Executive Vice-President Jennifer Zelmer says that rather than stipulating how its provincial and territorial government partners make decisions around the technologies they purchase with federal grants from Infoway, the federal agency has always focused "on the end result" in promoting usage of electronic records.

"The downside of this approach has been that vendors didn't market interoperable systems," says Cafazzo. "There is growing appreciation that many prov- inces cannot solve the interoperability problem on their own."

Infoway spokesperson Dan Strasbourg says project sponsors are now required to select software that is certified on interoperability.

Data from a 2015 survey by the Commonwealth Fund, indicate that EHR use by Canadian primary care physicians has tripled over the past decade, to about $73 \%$.

Robin Osborn, the survey's lead author, agrees that these are encouraging results for Infoway (which co-funded the survey). But he says progress on the clinical use of records is still hampered by the interoperability disconnect. For example, a recent international survey published in 2015 in Health Affairs indicates that only $19 \%$ of primary care clinicians could exchange patient summaries with clinicians outside their practices.

Robyn Tamblyn, scientific director of the Canadian Institutes of Health Research's Institute of Health Services and Policy Research, says establishing Infoway outside of a national health care organization helped create a "disconnect" with actual clinical needs. In a 2013 paper in BMC Public Health, Tamblyn and coauthors concluded that rather than continue to rely on Infoway, the Public Health Agency of Canada should develop the expertise to lead policy.

Tamblyn's questioning of the need for Ottawa to continue funding Infoway was echoed in a July 2015 report by the federal Advisory Panel on Healthcare Innovation. Noting that "Canada is being held back by incomplete interoperability, as well as gaps in uptake of electronic medical records," the panel recommended the federal government tackle ehealth in an agency with greater clinical engagement.

Dr. Jane Philpott, the new federal minister of health, is assessing federal ehealth efforts, confirms spokesman Andrew MacKendrick. "This topic is part of her mandate letter and as she works with her provincial and territorial counterparts in the coming months there will be more to update Canadians on." - Paul Christopher Webster, Toronto, Ont. 